\title{
Metode Kreatif Vocalizing Untuk Meningkatkan Kualitas Bernyanyi Paduan Suara
}

\author{
Christi Debora Lucas \\ Institut Sekolah Tinggi Filsafat Jaffray Makassar \\ christidlucas123@gmail.com
}

\begin{abstract}
The purpose of this study is to explain the importance of vocalizing creative methods that can improve the quality of choral singing. Every choir member or singer needs to apply vocalizing as the main basis in singing and the coach must master the correct theory and be able to generate new ideas in leading vocal warm-ups. Because vocalizing is so important for choirs and singers. The research method used in the preparation of this scientific paper is a qualitative research method, namely by conducting interviews with several respondents, looking for books related to this scientific work, dictionaries and journals. The purpose of this scientific work is as follows: first, so that every member of the choir or singers, is able to achieve quality results when singing. Second, to explain the importance of the creative method of vocalizing on the quality of choral singing. The third is to explain how creative vocalizing methods can improve the quality of choral singing. The conclusion from the results of this analysis are: The vocalizing creative method is a new idea and innovation that can be developed, so that in its implementation the singer does not feel bored and monotonous, but makes the practice more creative and effective.
\end{abstract}

Keywords: method creative; vocalizing; choir

\section{Abstrak}

Tujuan penelitian ini adalah menjelaskan tentang pentingnya metode kreatif vocalizing yang dapat meningkatkan kualitas bernyanyi paduan suara. Setiap anggota paduan suara atau para penyanyi perlu menerapkan vocalizing sebagai dasar yang utama dalam bernyanyi dan pelatih harus menguasai teori yang benar dan mampu menghasilkan ideide yang baru dalam memimpin pemanasan vokal. Sebab vocalizing begitu penting bagi paduan suara dan para penyanyi. Metode penelitian yang dipakai dalam penyusunan karya ilmiah ini adalah metode penelitian kualitatif yakni dengan melakukan wawancara kepada beberapa responden, mencari buku-buku yang berkaitan dengan karya ilmiah ini, kamus dan jurnal. Tujuan dari penelitian ini adalah sebagai berikut: pertama, untuk menjelaskan pentingnya metode kreatif vocalizing pada kualitas bernyanyi paduan suara. Kedua, untuk menjelaskan bagaimana metode kreatif vocalizing yang dapat meningkatkan kualitas bernyanyi paduan suara. Kesimpulan dari analisis ini adalah: metode kreatif vocalizing sangat penting dilakukan karena merupakan dasar yang paling utama dalam bernyanyi dan pelatih mampu menerapkan ide dan inovasi baru yang dapat dikembangkan, sehingga dalam pelaksanaannya penyanyi tidak merasa bosan dan monoton, melainkan membuat latihan lebih kreatif dan efektif.

Kata Kunci: metode kreatif, vocalizing, paduan suara 


\section{Pendahuluan}

Menyanyi atau bernyanyi, baik secara individu maupun secara kelompok, kelas amatiran apalagi tingkat profesional, pasti tidak terlepas dari latihan. Satu aktifitas yang sangat penting dalam proses latihan, adalah pemanasan. Biasanya pemanasan ini terbagi atas dua sesi. Sesi pertama adalah pemanasan fisik yang bertujuan untuk melenturkan otot-otot; sesi kedua yaitu pemanasan vokal dan konsonan yang tujuannya untuk meluweskan pita suara (Listya, 2007). Tentu saja kedua bentuk pemanasan ini dilakukan pada awal latihan, sebelum masuk pada latihan notasi atau solmisasi dan latihan dengan syair lagu secara lengkap.

Baik pemanasan fisik maupun pemanasan vokal, sesungguhnya keduanya sama penting untuk diterapkan sekaligus dikuasai dan dipahami oleh setiap penyanyi yang mau menghasilkan suara yang baik saat menyanyi. Penerapannya pada setiap orang atau pada setiap kelompok penyanyi biasanya tergantung kepada pelatih; dan jika berkenan teknik ini dapat juga dilakukan sendiri oleh masing-masing penyanyi di luar latihan, tentu setelah mengetahui prosesnya. Artinya, baik sendirian atau berkelompok, vocalizing dapat dilakukan.

Teknik vocalizing dengan membunyikan nada-nada dalam huruf hidup atau vokal: a-e-i-o-u, dan huruf mati atau konsonan: h-r-s-m-n-ng, dan seterusnya, merupakan pemanasan atau warming up yang wajib dilakukan. Selain untuk mempermudah pembentukan suara, kepentingan vocalizing adalah untuk melatih kemampuan menjangkau nada-nada yang tinggi maupun yang rendah; serta untuk mengetahui letak dan manfaat masing-masing vokal dan kosonan pada saat menyanyi sesuai range yang dapat dicapai oleh setiap penyanyi (Novrida, 2017).

Para penyanyi dalam paduan suara maupun penyanyi dalam bentuk kelompok musik lainnya, bahkan penyanyi solo sekalipun, vocalizing menjadi sebuah 'ritual' atau kebiasaan wajib yang tidak boleh diabaikan. Mengabaikan vocalizing sama dengan membiarkan suara penyanyi ataupun paduan tidak maksimal. Artinya, bentuk vokal maupun konsonan tidak terdengar jelas dan tepat sebagaimana seharusnya, karena otototot pendukung suara tidak lentur dan mengakibatkan pita suara terasa kaku dan tegang. Sebaliknya, dengan vocalizing sebelum menyanyi, akan lebih mudah bagi penyanyi untuk memahami cara kerja alat-alat ucap atau artikulasi. Bahkan bagi pelatih, mengutamakan vocalizing dalam setiap latihan sangat diperlukan. Karena sebagai pelatih sudah menjadi tanggung jawabnya untuk membentuk suara penyanyi secara benar dan tepat agar penyanyi menghasilkan suara yang indah, stabil, dan tidak false.

Sebagai salah satu teknik dalam latihan paduan suara, menerapkan vocalizing tidak sulit, tetapi perlu dilakukan secara terus-menerus dan rutin. Dalam menerapkan vocalizing sangat dibutuhkan kreativitas dari seorang pemimpin paduan suara, sehingga ada karya dan ide-ide yang baru dalam pemanasan vokal. Aktivitas paduan suara adalah kerja keras dalam latihan (Liturgi, 2019). Para pelatih mengarahkan, membimbing, dan melatih pelaksanaan vocalizing secara cermat dan tepat agar vocal placement atau vokal dan konsonan bekerja sesuai bunyi dan tempatnya. 
Berdasarkan pengamatan penulis dalam melatih paduan suara di lapangan bahkan terlibat menjadi anggota paduan suara, vocalizing sering dihindari oleh anggota paduan suara. Bahkan ada yang beranggapan bahwa vocalizing hanya formalitas semata dan kesia-siaan waktu, sehingga hal ini menghambat kelancaran latihan dan seringkali harus mengulang kembali latihan dari awal. Dari pengalaman ini timbul pemikiran bahwa pelaksanaan latihan sedikitnya harus memenuhi kaidah non teknis juga, misalnya: adanya inisiatif dari setiap anggota paduan suara dalam latihan secara mandiri, disiplin waktu untuk memulai dan mengakhiri latihan, tetapkan target yang hendak dicapai pada setiap jam latihan, apresiasi atas kesetiaan anggota untuk hadir, serta perlu menekankan pada anggota untuk senantiasa menjaga dan memelihara ketertiban latihan. Dengan demikian latihan bukan hanya secara teknis saja, melainkan perlu juga memperhatikan hal non teknis seperti di atas sehingga adanya peningkatan. Dan tujuan dari semua itu tentu saja agar setiap anggota paduan suara atau penyanyi dapat mencapai hasil yang berkualitas saat bernyanyi (Sari, 2019).

Menjalankan konsep teknik vocalizing dalam penyelenggaraan paduan suara, ibarat seorang ibu yang terus-menerus mengajar anak-anaknya berbicara dan berperilaku baik dalam kehidupan sehari-hari. Mengulang dan mencontohkan setiap bagian dari materi latihan menjadi keharusan yang sampai sekarang masih relevan untuk dilakukan seorang pelatih. Harus disadari, bahwa konsep latihan merupakan proses perubahan tingkah laku, artinya hasil yang diharapkan dari latihan vocalizing sudah menetap dalam diri penyanyi. Juga perlu menyadari, keberhasilan dalam latihan seringkali dipengaruhi oleh kondisi seseorang, maksudnya penyanyi paduan suara. Bahwa setiap anggota tidak dapat disamakan, karena kondisi mental maupun intelektual, apalagi motivasi latihan setiap anggota berbeda sehingga hasilnya pun berbeda. Harus terus-menerus diingatkan dan dicontohkan, sekaligus diberi pemahaman tentang makna dan kepentingan vocalizing dalam latihan sebagai upaya untuk membentuk dan menghasilkan suara yang berkualitas.

Untuk efisiennya vocalizing dan untuk menghindari anggapan sebagian penyanyi paduan suara bahwa vocalizing hal yang membosankan sehingga tidak ada kemauan untuk latihan pemanasan, ada baiknya pelatih memberikan arahan, ajaran, petunjuk, dan praktik dengan menggunakan cara-cara yang menarik perhatian, mudah diterapkan, dan menyenangkan. Pastikan semua anggota mendengar dan menyimak arahan untuk kemudian melakukan latihan bersama-sama tanpa merasa terbeban dan terpaksa. Seringkali keberhasilan dipengaruhi situasi dan kondisi mental penyanyi, oleh sebab itu perlunya menerapkan vocalizing setiap kali latihan dan harus diingatkan berulang-ulang tanpa jenuh.

Menambah pengetahuan, keterampilan, dan motivasi yang kuat untuk menyanyi dengan indah akan menghasilkan paduan suara yang baik. Walaupun sudah tergabung dalam paduan suara profesional bahkan sudah menjadi penyanyi yang handal, manfaat vocalizing haruslah diterapkan sehingga mampu mencapai vocal yang stabil, luwes saat bernyanyi, rileks, dan tidak kaku (Okatara, 2011). 
Berdasarkan latar belakang yang sudah diuraikan di atas, penulis merumuskan pokok masalah dalam penulisan ini, yaitu: pertama, apa pentingnya metode kreatif vocalizing pada kualitas bernyanyi paduan suara? Kedua, bagaimana metode kreatif vocalizing yang dapat meningkatkan kualitas bernyanyi paduan suara? Adapun tujuan penulisan yang hendak dicapai dalam penulisan karya ilmiah ini adalah sebagai berikut:pertama, untuk mengetahui pentingnya vocalizing pada kualitas bernyanyi paduan suara. Kedua, untuk mengetahui metode kreatif vocalizing yang dapat meningkatkan kualitas bernyanyi paduan suara.

\section{Metode}

Dalam penulisan karya ilmiah ini, penulis akan menjelaskan metode kreatif vocalizing dengan menggunakan penelitian kualitatif yang berupa wawancara dengan pelatih paduan suara yang informan, bahkan menggunakan kepustakaan yang berkaitan dengan karya ilmiah ini berupa, jurnal, kamus, artikel internet, dan buku-buku yang berkaitan dengan judul (Johan Setiawan, 2018). Dalam hal ini, peneliti memakai jenis atau metode yang berupa penelitian kualitatif yang melihat data dengan teliti dan mengumpulkan menjadi satu pendapat dari responden. Cara dalam menganalisis data kualitatif ialah pendapat melalui ide-ide dalam konsep data secara menyeluruh, dengan menggunakan strategi yang dipakai untuk mengubah atau menyalin data yang belum matang ke dalam bentuk penjelasan atau deskripsi dari fakta yang sedang diteliti dan dipelajari (Junaid, 2016). Dalam hal ini proses teknik analisis data menggunakan metode kualitatif yang dikemukakan sebagai berikut. Penarikan kesimpulan dan verifikasi, adalah bagian yang dilakukan peneliti secara terus-menerus mulai dari teknik pengumpulan data, menuliskan proses dalam catatan teori bahkan penjelasan-penjelasan yang berkaitan dengan kreatif vocalizing (Rijali, 2019). Teknik analisis data ini, untuk mengetahui metode kreatif vocalizing dalam meningkatkan kualitas bernyanyi paduan suara. Adapun tujuan penelitian adalah untuk mengetahui metode kreatif vocalizing dalam meningkatkan kualitas bernyanyi paduan suara yang diterapkan responden. Data diperoleh dari hasil wawancara dengan beberapa pelatih paduan suara. Setelah data penelitian terkumpul, baru kemudian penulis melakukan analisis.

\section{Hasil dan Pembahasan}

Pada bab ini penulis menggunakan metode penelitian kualitatif dan akan menguraikan serta menjelaskan data dengan hasil penelitian tentang masalah yang telah diuraikan sebelumnya pada Bab I. Untuk memperoleh data, penulis melakukan penelitian melalui wawancara dengan beberapa pelatih paduan suara yang menerapkan metode kreatif vocalizing dalam latihannya. Setelah memperhatikan dan mengamati semua data yang telah terkumpul, maka penulis membuat analisis data wawancara sebagai hasil dari penelitian. Dengan demikian semua data yang sudah dikelompokkan berdasarkan pokok masalah menjadi jelas, sehingga mempermudah para pembaca untuk mengerti dan memahami pembahasan tersebut. Adapun para pelatih paduan suara yang penulis wawancarai merupakan alumni yang semasa kuliah menjadi pelatih Gita Choir. Sekarang 
para responden ini menjadi pelatih-pelatih handal, bukan hanya paduan suara di gereja saja, tetapi juga di paduan suara non gereja. Berikut adalah nama-nama pelatih paduan suara yang menerapkan metode kreatif vocalizing:

1. Jordan Timotius, pelatih paduan suara GKII Jemaat Bethel Sintang Kalimantan Barat

2. Spiner Gun, pelatih Paduan Suara GKII Jemaat Tanjung Nanga Kalimantan Utara

3. Laura Megawaty Manalu, pelatih PSA\&T (BZCC) GPIB Jemaat Bukit Zaitun Makassar.

4. Frangky Lawendatu, LEWI Children Choir Melak Kutai Barat Kalimantan Timur

5. Orel Kojo, pelatih PS Jemaat GKKK Bone Sulawesi Selatan.

Metode kreatif vocalizing merupakan ide dan inovasi baru yang dapat dikembangkan, sehingga dalam pelaksanaannya penyanyi tidak merasa bosan dan monoton, sebaliknya membuat latihan lebih kreatif dan efektif. Metode kreatif vocalizing semua tepat dilakukan, jika disesuaikan penggunaannya dengan kebutuhan anggota paduan suara. Metode kreatif vocalizing, dapat dilakukan dengan menyesuaikan tingkat kemampuan anggota paduan suara yang berantusias dan lebih rileks lagi. Vocalizing yang dilakukan secara rutin disertai disiplin niscaya musikalitas dan vokal penyanyi akan meningkat secara signifikan.

Unsur yang memengaruhi sehingga kualitas bernyanyi paduan suara dapat meningkat, karena: adanya kebersamaan, keakraban, keharmonisan, dan kesatuan yang erat antar anggota dan antar anggota dengan pelatih. Meningkatkan kualitas bernyanyi memerlukan ketekunan, kedisiplinan, tekad dan niat sehingga tercapai hasil yang maksimal. Kemampuan, pengetahuan, wawasan dan pengalaman seorang pelatih yang memahami tahapan-tahapan vocalizing, akan menambah tingkat kepercayaan penyanyi terhadap pelatih, dan akan membangun rasa percaya diri penyanyi, baik dalam latihan persiapan maupun saat penampilan paduan suara.

Pertama, metode kreatif vocalizing berdasarkan hasil wawancara dari pelatih yaitu lagu-lagu yang familiar dalam pengucapannya yang membutuhkan bunyi artikulasi dan diksi, atau konsonan saat dinyanyikan, metode bersiul, menguap, pelangi untuk legato, berimajinasi, latihan pernapasan, dan melakukan pemanasan fisik. Setiap pelatih sangat penting menerapkan metode kreatif vocalizing untuk meningkatkan kualitas bernyanyi paduan suara. Vocalizing tidak dapat dilepaskan dari kegiatan paduan suara, karena vocalizing yang benar dan tepat merupakan dasar utama yang harus diketahui dan dikuasai para penyanyi paduan suara, untuk meningkatkan kualitas bernyanyi yang baik.

Kedua, metode kreatif vocalizing yang sering dilakukan oleh pelatih paduan suara saat melakukan pemanasan vokal yaitu latihan pernapasan, karena itu menjadi dasar yang kuat dalam bernyanyi. Pelatih dapat menjelaskan ke penyanyi tentang metode pernapasan dalam bernyanyi dengan pemanasan vokal seperti a-o-u-e-i. Latihan tersebut dapat dikembangkan secara inovatif, diterapkan sesuai lagu yang akan dilatih, serta melihat kondisi dan kemampuan anggota paduan suara dan penyanyi. Karya yang baru dalam penerapan metode kreatif vocalizing, akan membuat anggota betah berlatih bahkan tidak merasa bosan dan monoton.

Keempat, semua metode kreatif vocalizing yang diterapkan kepada anggota paduan suara atau penyanyi sangat baik, jika dilakukan dengan benar. Metode kreatif 
vocalizing hanya akan tercapai jika pelatih maupun penyanyi memiliki kemauan dan kebersamaan dalam menerapkan disiplin, ketekunan, semangat berlatih, dan bersedia mengembangkan ide-ide baru serta menerapkannya secara variatif dan imajinatif.

Kelima, metode kreatif vocalizing dapat diterapkan secara bersamaan dalam paduan suara, tetapi juga dapat dilakukan secara mandiri atau individu. Sangat dianjurkan supaya vocalizing diterapkan secara rutin sebelum paduan suara memulai latihan bernyanyi dengan solmisasi dan syair lagu. Jika metode kreatif vocalizing dapat diterapkan dengan baik, tepat, dilakukan dengan niat dan tekad yang tulus, niscaya paduan suara akan menghasilkan kualitas suara yang maksimal dalam penampilan atau pelayanannya.

\section{Implikasi}

Setiap pelatih paduan suara bahkan pemimpin pemanasan vokal, penting melakukan dan menghasilkan ide-ide yang kreatif dalam menerapkan vocalizing. Lebih dari pada itu, vocalizing sangat penting dilakukan baik penyanyi solo, duet, trio, bahkan paduan suara, sehingga setiap penyanyi akan menghasilkan kualitas suara yang lebih baik dan luwes.

\section{Rekomendasi untuk Penelitian Lanjutan}

Dalam penelitian ini tentunya belum sempurna, jadi penulis memberikan kesempatan kepada peneliti-peneliti selanjutnya yang ingin meneliti dan mengembangkan metode kreatif vocalizing dengan ide-ide yang baru untuk meningkatkan kualitas bernyanyi paduan suara.

\section{Kesimpulan}

Berdasarkan hasil teori yang sudah diuraikan maupun hasil penelitian yang telah dilakukan untuk melengkapi pembahasan karya tulis ilmiah yang berjudul "Metode Kreatif Vocalizing untuk Meningkatkan Kualitas Bernyanyi Paduan Suara," maka penulis membuat kesimpulan sebagai berikut ini. Vocalizing dapat dilakukan dengan menggunakan lagu-lagu yang familiar, melakukan imajinasi dalam vocalizing, menggunakan metode bersiul, metode menguap sambil bernyanyi, melakukan pemanasan fisik, dan melakukan metode kreatif vocalizing dengan cara melatih pengucapan di depan cermin.

\section{Rujukan}

A. Rahmadani Datu, S. (2019). Pelatihan Teknik Vokal Untuk Meningkatkan Kemampuan Bernyanyi Pada Siswa Dalam Kegiatan Ekstrakurikuler Paduan Suara SMA Negeri 13 Bone. 6(4), 8.

Johan Setiawan, A. A. (2018). Metodologi Penelitian Kualitatif. Jejak Publisher. Junaid, I. (2016). Analisis Data Kualitatif. 10(1), 65.

Listya, R. A. (2007). A-Z Direksi Paduan SUara. Yayasan Musik Gereja di Indonesia. Liturgi, T. P. M. (2019). Menjadi Dirigen III Membina Paduan Suara. Pusat Musik Liturgi. 
Novrida, M. (2017). Komunikasi Instruksional Pelatih Dalam Melatih Teknik Bernyanyi Paduan Suara Cantabile Pekanbaru. 4(2), 3.

Okatara, B. (2011). 6 Jam Jago Teknik Olah Vokal Menuju Penyanyi Profesional. Gudang Ilmu.

Rijali, A. (2019). Analisis Data Kualitatif. Alhadharah: Jurnal Ilmu Dakwah, 17(33), 81. https://doi.org/10.18592/alhadharah.v17i33.2374

Sari, A. R. D. (2019). Pelatihan Teknik Vokal Untuk Meningkatkan Kemampuan Bernyanyi Pada Siswa Dalam Kegiatan Ekstrakurikuler Paduan Suara Sma Negeri 13 Bone. 6(4), 23. 